\title{
Effect of the Problem-based Learning (PBL) Method with the Integration of Interactive Simulation on the Physical Sciences Conceptual Understanding of the Moroccan Common Core Learners
}

\author{
Cherif Alaoui Mrani*, Abdelkrim El hajjami, Jalal Khouna \\ Laboratory of Computer and Interdisciplinary Physic (LIPI), ENS (Ecole Normale supérieure), Sidi Mohammed Ben Abdellah \\ University, Morocco
}

Received July 12, 2020; Revised September 7, 2020; Accepted September 17, 2020

\section{Cite This Paper in the following Citation Styles}

(a): [1] Cherif Alaoui Mrani, Abdelkrim El hajjami, Jalal Khouna, "Effect of the Problem-based Learning (PBL) Method with the Integration of Interactive Simulation on the Physical Sciences Conceptual Understanding of the Moroccan Common Core Learners," Universal Journal of Educational Research, Vol. 8, No. 11, pp. 5281 - 5298, 2020. DOI: 10.13189/ujer.2020.081129.

(b): Cherif Alaoui Mrani, Abdelkrim El hajjami, Jalal Khouna (2020). Effect of the Problem-based Learning (PBL) Method with the Integration of Interactive Simulation on the Physical Sciences Conceptual Understanding of the Moroccan Common Core Learners. Universal Journal of Educational Research, 8(11), 5281 - 5298. DOI: 10.13189/ujer.2020.081129.

Copyright $\bigcirc 2020$ by authors, all rights reserved. Authors agree that this article remains permanently open access under the terms of the Creative Commons Attribution License 4.0 International License

\begin{abstract}
Thanks to its advantages in improving the learning, the understanding and the performance of learners, the interactive simulations have become among the main tools recommended by many researches as an alternative to the traditional pedagogical tools. Indeed, the forms and the objectives of the integration of simulations in teaching and learning process are varied depending on the pedagogical needs of the user, as well as according to the adopted learning methods and activities. In this contribution we aim to study the impact of problem-based learning (PBL) using interactive simulation, on the understanding of the concepts related to the rotational equilibrium, taught in common core science level. The concepts covered by this study are force and inventory, torque and Newton's second law for rotation. We first propose a selection grid to help teachers to choose the appropriate simulation product for a given problem-based learning activity, we later perform the experience to compare the performance of the students in the control group (who solve the problem using traditional method) and the students in the experimental group (who use the simulation tool) based on the pre-test and post-test methodology. The simulation tool used in the experimental
\end{abstract}

part is determined using the grid that we have developed. Obtained results have shown that the use of interactive simulation has a positive effect on student's conceptual understanding, if it was properly integrated into an educational context.

Keywords Interactive Simulation, Problem-based Learning, Conceptual Understanding, Rotational Equilibrium, Physics

\section{Introduction}

Since 2002, all Moroccan school teaching cycles have recorded many advances in pedagogical plan: the curricula have been revised and new pedagogical orientations have been adopted, such as the competency-based approach (CBA). CBA puts the learner in the center of the teaching-learning process, in other words, (s)he is responsible for her/his learning and it is up to him/her to build her/his own knowledge. The teacher no longer has to take full responsibility for the design and management of 
activities, it can simply take advantages from available tools, notably information and communication technologies (ICT) designed for education. Psychologists and educators have long observed that we learn better, more when we are active and autonomous, this means that the learning tools, strategies and methods which guarantee a high level of autonomy to the learner and can make $\mathrm{him} / \mathrm{her}$ responsible for her/his learning, are increasingly desirable to adopt. From this vision, the interest in computer simulation and problem-based learning (PBL) has been increased, especially when teaching of the physical science. Computer simulation improves students' conceptual understanding [1], and it can positively influence student satisfaction, initiative and engagement [2], as well as their perception of the school environment [3], computer simulation also makes learners more interested in the course, and thus improves their academic results [4]. The PBL is a method that aims to make operational the various specific disciplinary knowledge taught while targeting other training objectives such as autonomy, development of communication skills, problem solving, improving effective document search strategies, group learning and finally the transfer and integration of knowledge [5]. In addition, the PBL method improves students' motivation to learn by giving them control and responsibility over the work they undertake [6], and improves learners' engagement in metacognitive processes while ruminating on the problem-solving process [7], as well as developing higher thinking ability of control and including critical thinking and creative thought [8]. In this work, we highlight the appropriateness of using interactive computer simulations as a support for learning in the problem-based approach. In fact, the use of problem-based learning method and computer simulation tools in a single learning strategy provokes a kind of integrative learning, that is to say that PBL method and computer simulation can support each other to achieve common learning goals. The simulation is considered as the most interesting in the constructivist approach to learning using ICT [9]. Using simulation in PBL activities can activate students' basic procedural skills in science, like observing, measuring, communicating, classifying and predicting, as well as procedural skills specifically those integrated into scientific approach, such as controlling variables, formulating hypotheses, interpreting data, experimenting and formulating models [10]. Physical science learning is a process that is basically based on observation and experimentation, the problem-based learning method integrating ICT is considered among the solutions of low performance problem. The PBL method has shown a great consistency after being integrated with ICT, given that the use of ICT can enrich and activate this type of learning, and at the same time, this learning method highlights more clearly the benefits of ICT. In confirmation of this idea, Lebrun [11] considers that ICT can contribute to the development of pedagogies only if it is accompanied by pedagogical method based on more incentive and interactive methods, being supported by new roles for teachers and learners, and is finalized in the development of social skills and professional. On their side, Collins et al. [12] confirm that the learners should be given control and freedom of choice over certain learning strategies such as comparison and discovery, by facilitating concentration and reflection on their learning process, through the use of Computer Assisted Teaching (CAT). Simulation as a principal pillar of using the ICT in education is not far from confirming the same idea; de Jong et al. [13] have shown that learning by means of simulation is more effective in an environment which offers possibilities of investigation and discovery.

In the theoretical part of this work, we develop a selection grid to choose the simulation product compatible with the environment of the problem-based learning method. In the experimental part, we examine the impact of adopting the selected product by using the proposed grid, on the performance of the learners in conceptual understanding. We restrict the use of simulation to understand some concepts related to the topic of studying equilibrium of a solid object rotatable around a fixed axis. To do so, we adopt the pre-test and post-test methodology to compare the performance of the two groups. The first group resolves the problem under traditional conditions; on the other side, the experimental group manipulates the selected simulation product to solve the same problem.

\section{Problematic}

Morocco is one of the developing countries whose level of student performance remains relatively low. Despite efforts to partially improve the quality of learning, the results of international and national surveys reveal low levels of achievement [14,15]. Many contributions show that this problem is justified by several reasons, such as the lack of motivation, the spread of traditional teaching methods and tools, the absent of equipped laboratory, etc. To handle this problem, the interactive multimedia is used to make students motivated and helps them to improve their learning capacity, by making the activities more interesting, effective and easy to understand.

The integration of ICT in education is accompanied by constant questioning about the expected and potential effects of these tools on learning and teaching, as well about the mechanisms for selecting the appropriate digital product given a learning situation. Thus, we will try through this study to answer the following questions: Among existing simulation products, how can we determine those suitable for problem-based learning activities? Could the pedagogical use of computer simulations have a positive impact on improving the understanding of rotational equilibrium concepts in the common core sciences? 


\section{Mechanism to Choose the Appropriate Simulation Tool}

In fact, the process of selecting the appropriate simulation has the same importance as the classroom experimentation process. The type and characteristics of a simulation product, such as the suitability for the approved learning method, are among the main determinants of its successful use in the classroom. Therefore, the teacher who intends to use this technology in classroom activities must have a mechanism to determine the appropriate simulation, especially since these tools have become abundant in websites. In this section, we see that the elaboration of a selection grid can help and encourage teachers to integrate the simulation into classroom activities. To determine the themes of the grid, we recourse to the multimedia assessment methods introduced by Patrick Benazet in [16]. We also take benefits from previous studies related to the contribution of simulations to support learning using problem solving method. The grid engineering and the mechanism used to treat the results were inspired from the contribution of Khouna et al. [17], as a part of the selection of a competencies approach based educational game. Therefore, the selection criteria will focus on the following points: Product response to problem-based learning requirements; Usefulness of simulation product; Product contribution to enhance motivation and engagement; Content of simulation product.

\subsection{When is Simulation Consistent with the Problem-based Learning Method?}

The problem-based approach is a pedagogical approach centered around the learner; it aims to develop skills by making the learner facing significant and real problem, these situations are designed to be similar as much as possible to the daily problems. In problem-based learning, learners are grouped into teams to solve together a problem that the teacher has suggested, a problem for which they have received no specific training, this situation helps them to learn content and develop problem-solving skills [18]. In the problem-based learning method, the learner must assume responsibility for her/his own learning and must be seen as a problem solver, as well as being a partner and collaborator in the learning process with others [19]. In PBL activities, the learners distribute the tasks among themselves and share their skills, they try to be independent of the teacher as much as possible using all the available resources. According to Gallagher et al. [20], the essential elements of problem-based learning can be determined in four elements: 1) Problem should focus on important scientific concepts; 2) There should be opportunities to test student ideas through laboratory or field experience; 3 ) Learners must manage their own data; 4) Students should present their solutions.
According to Gredler [21], the main characteristics of the constructive learning environment supported by ICT are: (a) An adequate model of the complex real-world situation with which the student interacts; (b) A defined role for each participant, with responsibilities and constraints; (c) A data-rich environment that permits students to execute a range of strategies, from targeted to "shotgun" decision making; (d) and feedback for participant actions in the form of changes in the problem or situation. Weiner et al. [22] state that for the computer simulation to be appropriate to the specified problem-based learning environment, it must not be the reproduction of a system given to students to digest, but rather be given to them to "discover" the system's behavior by exploration and manipulation. Therefore, the degree to which simulation responds to the requirements of problem-based learning activities can be assessed, first, by examining the aspects that make it possible to determine the pedagogical approach on which the simulation is based; these aspects can be summarized as follows:

- The extent of the appropriateness of the simulation form for the problem-solving learning activity.

- The cognitive conflict that simulation creates for the learner.

- The flow of information that should allow knowledge to be woven into an additive mode rather than an alternate mode.

- The nature of the simulation, this point involves a reflection on the effect produced by each action of the learner.

- The rhythm of learning that must follow the learner's own rhythm.

- The nature of the simulation that should support exchange and discussion between students.

Second, by examining the elements that describe the problem presented to the learner, such as its novelty and realism.

\subsection{Usefulness}

The person-machine interface is evaluated according to its utility and its usability. Anglo-Saxons use the term usefulness to make reference to the utility and usability of user interface. In French context, we talk about ergonomics. The usability is the degree to which a product can be used by identified users, to achieve defined goals with effectiveness, efficiency and satisfaction, in a specified usage context [23]. Concerning the quality of a person-machine interaction, which is to say ease of learning and use [24], the functionalities are easy and pleasant to use. As for the utility, it determines if the product allows the user to achieve his work objectives [23] by providing him with what he needs. So, the usefulness of the interactive multimedia tool is evaluated by examining all of the following aspects of use, like readability, clarification of information, the information 
accessibility and the clarity of the feedback, etc.

\subsection{Motivation and Learner Performance}

In our study, we highly appreciate the role of motivation in improving learners' performance. Indeed, the performance is positively influenced by intrinsic motivation, in that the intrinsically motivated individuals enjoy an activity and spend more time developing their skills [25,26]. A student's understanding and academic results are very good when (s)he has intrinsic motivation [27-30]. But, how can we interpret the student motivation in a learning activity? How can an interactive simulation tool improve it?

According to [31,32], the student's motivation is regulated by three main factors: the degree of interest that the student can have in the topic, and his/her need for autonomy and competence, as well as with the development of his/her cognition. Based on these psychological ideas and a set of empirical studies, the authors talk about what we might call the motivational requirements of students during ICT-supported learning. In this context, Lepper et al. [33] link the increase intrinsic motivation of the learner with the challenge, the curiosity and the control. Wlodkowski [34] asserts that the intrinsic motivation of student is influenced by attitude, need, stimulation, emotions, competence and reinforcement. Therefore, the motivational aspect of an educational simulation can be assessed by examining some indicators such as the product ability to attract and maintain learners' attention, the challenges presented to learners, the enhancements that the simulation can provide to learners to reinforce their confidence in their skills, the level of practical activities, the richness and diversity of the learner-machine interaction, and the extent of correlation between the learning provided and the learners' prior learning, etc.

In the evaluation grid we have developed, we explain these criteria in the context of social constructivist learning supported by ICT where the learner faces dilemmas and questions.

\subsection{Content of Simulation Product}

Content is defined as the sum of the knowledge selected and specifically organized for the purpose of achieving one or more educational goals. This knowledge can be basic concepts, ideas, laws or mathematical relationships, etc. In the heuristic evaluation of information and communication systems, Nielsen [35] recommends evaluating the scientific content of a multimedia product based on two main pillars, namely:

- Relevance of the content to the subject: does the scientific content provided by the product to the user corresponds to its level of knowledge? Does this content is sufficient in terms of organization and richness to respond to the user's need for a specific purpose?

- Accuracy of the scientific content: does the presented scientific content is correct?

\subsection{Presentation of the Grid}

The choice of the evaluation grid focused on 25 criteria divided into four main themes as indicated in the Table 1.

The approved selection method passes through two steps:

- In the first step, the simulation tools are accepted or rejected on the basis of the results achieved in each theme separately: the product is selected for the next step if and only if it achieved a ratio equal to or greater than $50 \%$ of the total score assigned to each of the four evaluation themes.

- In the second step, the choice of the simulation product among those are filtered in the first step is performed based on the overall weighted score (OWS) given to each product. The overall weighted score is calculated using a weighting system based on the importance given to each theme. In fact, the objectives behind this work is to develop a grid that allows selecting a simulation product that meets the requirements of a problem-based learning method, so this topic should have a higher significance rate compared to the other three themes that have the same level of importance. Table 2 shows the weighting coefficients that we adopt in this study to calculate the overall weighted score.

The overall weighted score is calculated by Eq1:

OWS $=$ Content score $* 0.2+$ Motivation score* $0.2+$ Usefulness score*0.2 + Score of the suitability of the $\mathrm{PBL} * 0.4$

The overall weighted score is given by Table 3 using percentage score annotation. 
Table 1. Grid of the choice

\begin{tabular}{|c|c|c|c|c|}
\hline \multicolumn{2}{|c|}{ In each case, put a mark to express your opinion: $0:$ Not at all } & 0 & 1 & 2 \\
\hline \multirow{6}{*}{$\begin{array}{l}\text { Motivation } \\
\text { and } \\
\text { Engagement }\end{array}$} & $\begin{array}{l}\text { Type of simulation stimulates experimentation: the ability to capture and maintain the learner's attention } \\
\text { and interest, this can take the form of interactive decision-making instructions or interactive immersion, etc. }\end{array}$ & & & \\
\hline & Simulation presents challenges to the learners: the problem presented is neither too easy nor too difficult. & & & \\
\hline & $\begin{array}{l}\text { Simulation strengthens the learner's confidence in his or her skills: the questions of the problem are } \\
\text { organized to develop the learner's satisfaction and exploit his or her curiosity in his or her cognitive } \\
\text { potential. }\end{array}$ & & & \\
\hline & Practice: the opportunities to practice are numerous and diverse. & & & \\
\hline & $\begin{array}{l}\text { Supporting of student's engagement: the simulation provides a choice-rich environment to implement a } \\
\text { range of learning strategies, and gives the right to interact when new concepts are mentioned. }\end{array}$ & & & \\
\hline & $\begin{array}{l}\text { Personalization of learning: the simulation helps maintain the associative link between the learner's prior } \\
\text { knowledge and the knowledge, attitude or skill to be acquired. }\end{array}$ & & & \\
\hline \multirow{6}{*}{ Usefulness } & $\begin{array}{l}\text { Readability: the interface is very clear, easy to use and the objects are close to reality and with very high } \\
\text { quality. }\end{array}$ & & & \\
\hline & Clarification of information: the simulation provides alternative explanations, examples and feedback. & & & \\
\hline & Information accessibility: the ability to provide quick and easy access to information. & & & \\
\hline & Clarity of the feedback: feedback allowing learners to regularly progress is clear. & & & \\
\hline & Clarity of objectives: the learner easily and clearly understands the objectives and purpose of the simulation & & & \\
\hline & System support: the simulation offers system support (error correction, manual, tutorials, etc.) & & & \\
\hline \multirow{8}{*}{$\begin{array}{l}\text { Suitability } \\
\text { of the PBL } \\
\text { method }\end{array}$} & $\begin{array}{l}\text { Form of simulation: the form of simulation depends on the nature of the activity designed to solve the } \\
\text { problem. }\end{array}$ & & & \\
\hline & Reflection: the nature of the simulation involves a reflection on the effect produced by each learner's action. & & & \\
\hline & Realism of the problem: the problem presented is significant and real. & & & \\
\hline & Novelty of the problem: the problem presented has not been solved before. & & & \\
\hline & $\begin{array}{l}\text { Information control: information or presentation flow allows knowledge to be woven in an additive rather } \\
\text { than a substitute mode. }\end{array}$ & & & \\
\hline & $\begin{array}{l}\text { Highlighting a cognitive conflict: the simulation presents a source of intellectual dissatisfaction and is } \\
\text { highlighting a conceptual conflict between the initial assumptions and observations. }\end{array}$ & & & \\
\hline & $\begin{array}{l}\text { The rhythm of learning: the simulation product offers the possibility to progress according to the learner's } \\
\text { own rhythm. }\end{array}$ & & & \\
\hline & Interaction: the nature of simulation supports exchange and discussion between students. & & & \\
\hline \multirow{5}{*}{$\begin{array}{l}\text { Content of } \\
\text { the } \\
\text { Simulation }\end{array}$} & Validity of content: the scientific content is valid. & & & \\
\hline & Harmonization of goals: compliance of the content with the pedagogical goals of the activity. & & & \\
\hline & $\begin{array}{l}\text { Adequacy of content for the level concerned: the content is free of concepts and methods that do not } \\
\text { match with the student level. }\end{array}$ & & & \\
\hline & Content organization: consistency of content organization. & & & \\
\hline & Richness of content: simulation provides an environment rich with information that can be acquired. & & & \\
\hline
\end{tabular}

Table 2. Weighting coefficient

\begin{tabular}{|c|c|}
\hline Themes & Weighting Coefficient \\
\hline Content of the simulation & 0.2 \\
\hline The suitability of the PBL method & 0.4 \\
\hline Motivation and engagement & 0.2 \\
\hline Usefulness & 0.2 \\
\hline
\end{tabular}




\subsection{The Grid Use}

Indeed, the goal of developing the grid is to provide the physics teachers' community with an effective tool that can help them to choose the most appropriate simulation for problem-based learning activities. Thus, a physics teacher who teaches the same target level is assigned to conduct the research for simulation proposals to achieve the problem-based learning objective, and apply the different selection stages using the developed grid. After conducting the preliminary search on educational websites using the suitable keywords (interactive simulation, rotational equilibrium, torque, Newton's second law for rotation), as well as applying the proposed grid, three educational simulation products have been identified that can be adopted in our experiment. They are given as follows:

- $\quad$ PhET interactive simulation "Balancing Act- Balance lab" (https://phet.colorado.edu/);

- CK-12 interactive simulation "Drawbridge" (https://interactives.ck12.org/);

- CK-12 interactive simulation "See saw" (https://interactives.ck12.org/);

The overall scores for the three simulations are presented in the table 3.

Table 3. The evaluation results of the three products

\begin{tabular}{|c|c|c|c|}
\hline & See saw & Drawbridge & $\begin{array}{c}\text { PhET } \\
\text { product }\end{array}$ \\
\hline $\begin{array}{c}\text { Motivation and } \\
\text { engagement }\end{array}$ & $9 / 12$ & $8 / 12$ & $7 / 12$ \\
\hline Usefulness & $10 / 12$ & $10 / 12$ & $7 / 12$ \\
\hline $\begin{array}{c}\text { The suitability of the } \\
\text { PBL method }\end{array}$ & $12 / 16$ & $13 / 16$ & $10 / 16$ \\
\hline Simulation content & $8 / 10$ & $8 / 10$ & $7 / 10$ \\
\hline Overall weighted score & $77.66 \%$ & $78.50 \%$ & $62.32 \%$ \\
\hline
\end{tabular}

According to these results, the highest score is obtained by Drawbridge product, it will be used in the experiment phase.

\section{Product Description and its Use in Class}

According to the ck12 website, the "Drawbridge" product is an interactive simulation created by Dr Byron Philhour in December 22, 2014 as part of educational project of the CK-12 foundation. The principle of this interactive simulation is that when too much weight is placed on the bridge rotatable around a fixed axis, the cable that raises the bridge will be broken, and thus the bridge loses its equilibrium. The intriguing question, which is raised from the simulation to the learner is, how much weight can the drawbridge support? The answer to this question requires several assumptions such as, so as to keep the bridge in equilibrium state, the sum of the forces applied to the bridge must condense and the sum of the torques must be equal zero. But, when does this equilibrium get broken down? How much is too much? Does it depend on where you put that weight? Or does it depend on the angle the cable makes?

To more attract the attention of students and raise the degree of challenge in their cognitive ability, the simulation includes a survey questions called "challenge me". The survey includes the following questions: what is your best estimate of the breaking tension for the cable? Is there any cart that will break the cable if the angle is 90 degrees? What is the relationship between the tension in the cable and its angle?

The simulation provides the ability of interacting with these questions by changing the cart mass, the bridge length, and the cable angle $\alpha$, the learner can also move the cart left and right over the bridge. Using the simulation product, the learners can discover the relationship between the angle $\alpha$, the cable tension, the cart weight and the distance between the cart and the axis. In addition, they will extract the values of all these variables when cutting the cable. By responding, understanding and analyzing all this questions, the learners are invited to justify the results by applying Newton's second law for rotation and matching the theoretical results with the results of the virtual experiment.

Key physical concepts and laws that are mobilized out:

- The torque: torque is generated when forces are applied at some perpendicular distance.

- Newton's second law for rotation: for the bridge to stay up, the balance of forces and torques must be provided.

The tool animation window represented in Figure 1 shows the variables that the learner can control during the process of dealing with the problem. The directed arrows refer to the applied forces on the system. 


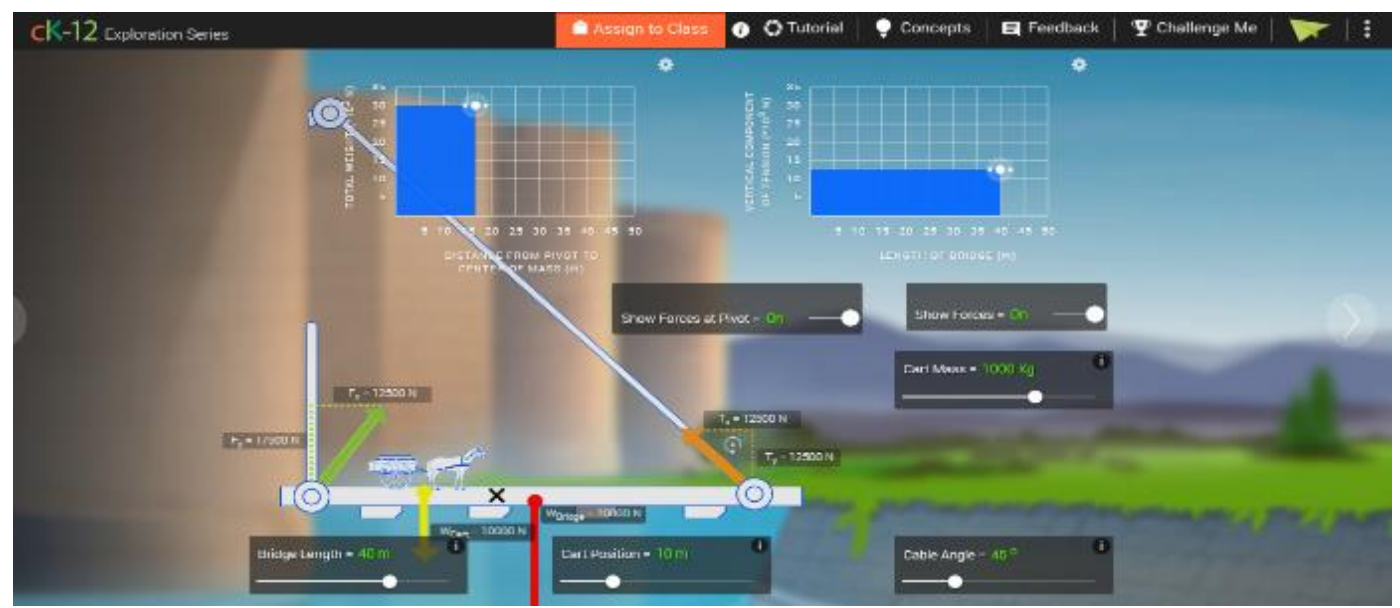

Figure 1. A screenshot showing some options offered by the product

\section{Product Testing}

\subsection{Methodological Approach}

In order to test the effect of the empirical use of the 'Drawbridge' simulation on the conceptual understanding of the learners, we adopted a pre-test and post-test method. The experiment was conducted in two main stages: the pre-processing stage and the processing stage.

\subsubsection{The Pre-processing Stage}

The experiment was carried out during the 2019-2020 academic year, using a sample of 40 students from Abu Bakr Al-Siddiq Es-Sfalat High School in Rissani city, Morocco, the average age of the experiment sample is 16 years old. By using the school management system "MASSAR", we divided the samples into two homogeneous groups, the experimental group consisted of 20 students, and the control group composed of 20 students. We make sure that some criteria are similar to guarantee a fair comparison of the performances of the two groups, the two groups are approximately at the same cognitive level, and their academic score rates are approaching. Both of the groups have learned some concepts in the course of the equilibrium of a solid object rotatable around a fixed axis, under the same teaching conditions so that the official instructions were respected. Both of the groups are then pre-tested to ensure their equivalence, before adopting the PBL method to enhance students' understanding and competencies.

\subsubsection{The processing Stage}

We ensure that the groups face the same problem that was included in the simulation. For the traditional set, the questions are reformulated to provide the values that the experimental group can obtain from the simulation (for example, when students conclude that the cable will be cut, we will give them a value of its tension when cutting and ask them to determine the angle). Both of the groups are invited to apply their theoretical knowledge related to the method of solving a problem at rotational equilibrium (specify the studied system and the forces acting on it; determine the axis and the positive direction of rotation; express the torque of the different forces and indicate whether they are driving the studied system in the positive or in the negative direction; and apply Newton's second law of rotation). The control group solved the problem under traditional conditions, while the experimental group used Drawbridge simulation according to a given pedagogical scenario. After completing the proposed pedagogical activity, we invited both of the groups to respond the post-test by using the paper and pen. The questions asked in the pre-test and post-test are identical, only the order of some of them has changed. The collected data are analyzed with XLSTAT 2020 software [36]. An alpha level of 0.05 was used in all analyzes. Below is the pedagogical design of the experiment. The details of the study are given in the Table 4.

\subsection{Measuring Instrument}

The construction of the test (Appendix 1) was achieved taking into account the program, the language of instruction, and the content of the proposed problem-based learning activity, as well as the best practices of the student understanding test assessment, we have been more focused on qualitative questions [37]. After having inventoried the targeted concepts, we created sufficiently relevant questions to test only one concept at a time, each concept being tested several times in different questions with diversified statements and sufficiently explicit to be understood. The test contains 17 questions, sometimes closed, sometimes open. Closed questions are multiple choices while open questions require analyses, manipulation of mathematical tools, etc. Table 5 provides a quick overview of the concepts targeted in the test as well as the number of questions included in the test. 
Table 4. Details of the experiment

\begin{tabular}{|c|c|c|}
\hline Experimental group & Control group & Duration \\
\hline $\begin{array}{l}\text { The simulation product was used in pairs by computer in the } \\
\text { multimedia room. }\end{array}$ & $\begin{array}{l}\text { In the physics classroom, we divide the students } \\
\text { into small groups. }\end{array}$ & \\
\hline $\begin{array}{l}\text { Learners are invited to define, explore and understand the problem } \\
\text { using the simulation: } \\
\text { - Identify significant information and the questions to be } \\
\text { answered. } \\
\text { - Clarify terms, concepts and formulate the objectives. } \\
\text { - Answer to the following three questions: "What do we know?" } \\
\text { What do we need to know? "How do we know?" }\end{array}$ & $\begin{array}{l}\text { The teacher suggests the problem using the table } \\
\text { and the technical sheet containing the problem } \\
\text { statement and questions. }\end{array}$ & $20 \mathrm{~min}$ \\
\hline $\begin{array}{l}\text { Search of the information: collecting the necessary information from } \\
\text { the various sources available. Such as tutorials and examples } \\
\text { integrated in the simulation. }\end{array}$ & $\begin{array}{l}\text { Students read the problem statement carefully and } \\
\text { seek additional information to better understand the } \\
\text { problem. }\end{array}$ & $25 \min$ \\
\hline $\begin{array}{l}\text { Analysis of the information, generate and discuss the possible } \\
\text { solutions. }\end{array}$ & $\begin{array}{l}\text { Students generate theoretically the solutions on the } \\
\text { basis of the torque definition and the Newton's } \\
\text { second law for rotation. }\end{array}$ & $25 \mathrm{~min}$ \\
\hline $\begin{array}{l}\text { Synthesis, objectification and critical feedback: } \\
\text { - Confront the various solutions or actions based on theoretical } \\
\text { and contextual information; } \\
\text { Determine the most suitable solution by reassessing the validity } \\
\text { and feasibility of their various proposed methods and select the } \\
\text { best means to solve the problem; } \\
\text { Review the process, the achievements and the strategies used } \\
\text { and assess the value of the produced knowledge. }\end{array}$ & $\begin{array}{l}\text { Students apply different theoretical formulas to } \\
\text { answer the questions asked. }\end{array}$ & $30 \mathrm{~min}$ \\
\hline Post-test & & $60 \mathrm{~min}$ \\
\hline $\begin{array}{l}\text { The available material: A computer connected to the CK-12 website } \\
\text { and a worksheet to note the procedure, the possible hypotheses, the } \\
\text { results and conclusions. }\end{array}$ & \multicolumn{2}{|c|}{$\begin{array}{l}\text { The available material: A technical sheet containing the problem } \\
\text { statement and the questions to be answered; a worksheet to note } \\
\text { the procedure, the results and the conclusions. }\end{array}$} \\
\hline
\end{tabular}

Table 5. Pedagogical sheet of the test

\begin{tabular}{|c|c|c|c|c|}
\hline Concept & Indicator & $\begin{array}{l}\text { Number of } \\
\text { questions }\end{array}$ & $\begin{array}{c}\text { Concept } \\
\text { importance }\end{array}$ & $\begin{array}{l}\text { Objectives to be } \\
\text { evaluated }\end{array}$ \\
\hline \multirow{3}{*}{$\begin{array}{l}\text { Force and } \\
\text { Inventory }\end{array}$} & Determine a system for study consistent with this lesson. & \multirow{3}{*}{3} & \multirow{3}{*}{$\begin{array}{l}3 / 20 \\
\text { Or } \\
15 \%\end{array}$} & \multirow{3}{*}{$\begin{array}{l}\text { The ability to } \\
\text { understand the } \\
\text { concept of force and } \\
\text { properly conduct the } \\
\text { force inventory. }\end{array}$} \\
\hline & Inventory of forces acting. & & & \\
\hline & Representation of force. & & & \\
\hline \multirow{8}{*}{ Torque } & $\begin{array}{l}\text { The rotational effect of the weight when the pivot passed } \\
\text { in object center of gravity. }\end{array}$ & \multirow{8}{*}{9} & \multirow{8}{*}{$\begin{array}{l}9 / 20 \\
\text { Or } \\
45 \%\end{array}$} & \multirow{8}{*}{$\begin{array}{l}\text { The ability to define, } \\
\text { express and apply the } \\
\text { concept of the torque. }\end{array}$} \\
\hline & $\begin{array}{l}\text { The rotational effect of different blocks hanging at } \\
\text { different positions around the center of rotation of a disc. }\end{array}$ & & & \\
\hline & $\begin{array}{l}\text { Give the definition of the Torque and give its } \\
\text { mathematical expression }\end{array}$ & & & \\
\hline & Deduce the conditions of rotation of a rotatable object. & & & \\
\hline & Trace the lever arm. & & & \\
\hline & Express the lever arm using trigonometric functions. & & & \\
\hline & $\begin{array}{l}\text { Analysis of the effect of the lever arm and force intensity } \\
\text { on torque value. }\end{array}$ & & & \\
\hline & $\begin{array}{l}\text { Analysis of the impact of the angle between the effect line } \\
\text { of the force and the target object to rotate one of its ends } \\
\text { (the other end is fixed) on the torque value. }\end{array}$ & & & \\
\hline \multirow{3}{*}{$\begin{array}{l}\text { Newton's } \\
\text { second law for } \\
\text { rotation }\end{array}$} & $\begin{array}{c}\text { Exploitation of Newton's second law for rotation to } \\
\text { determine the value of a variable. }\end{array}$ & \multirow{3}{*}{5} & \multirow{3}{*}{$\begin{array}{l}8 / 20 \\
\text { Or } \\
40 \%\end{array}$} & \multirow{3}{*}{$\begin{array}{l}\text { The ability to define, } \\
\text { express and apply the } \\
\text { Newton's second law } \\
\text { of rotation. }\end{array}$} \\
\hline & $\begin{array}{l}\text { Use the Newton's second law for rotation to analyze and } \\
\text { interpret a specific result. }\end{array}$ & & & \\
\hline & $\begin{array}{l}\text { Exploitation of Newton's second law for rotation to } \\
\text { explain the process of lifting a huge block using a lever } \\
\text { and another block is much less than that. }\end{array}$ & & & \\
\hline
\end{tabular}




\section{Results and Discussion}

For each question, the student response is dealt with either as a correct answer or as a false answer. Each question is linked to a single concept.

First, by comparing the average scores and variance of both groups in the pre-test, we ensure the homogeneity of the groups before performing any treatment. We then compare the average scores for both groups in the post-test. Then we compare the level of improvement in students' conceptual understanding, based on the results obtained in the test and in each concept separately.

\subsection{Check the Homogeneity of the Groups before Treatment}

The maximum score a student can obtain in the test is 20; the analyses of the results gathered in the pre-test for each group are presented by Figure 2 and Tables 6, 7 and 8 .
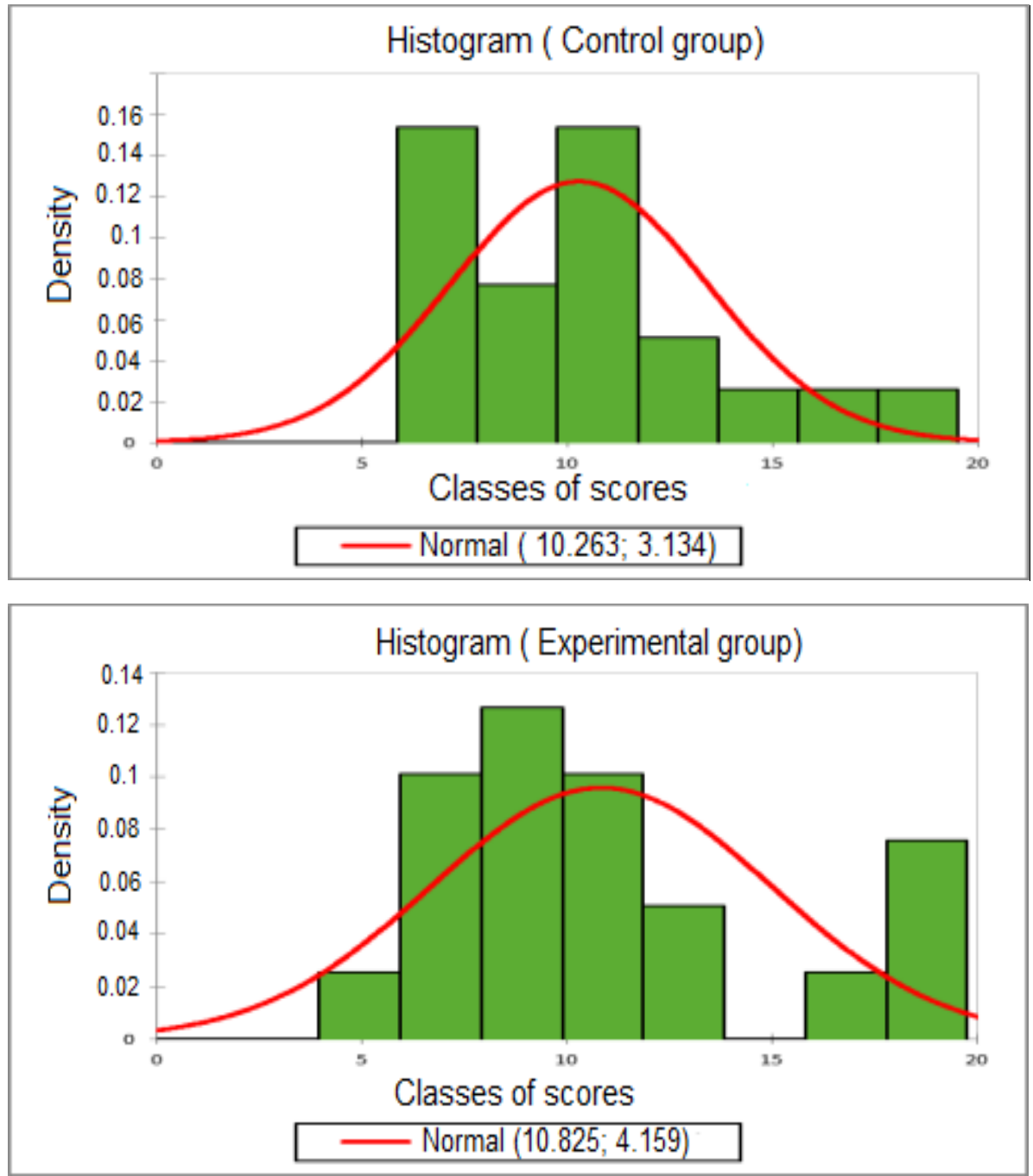

Figure 2. Graphs of the Normality test for the pretest results

Table 6. Descriptive statistics and Kolmogorov-Smirnov test for the pretest results

\begin{tabular}{|c|c|c|c|c|c|c|c|c|c|}
\hline Variable & Observations & $\begin{array}{c}\text { Obs. with } \\
\text { missing data }\end{array}$ & Min & Max & Average & S.D & D & $\begin{array}{c}\text { P-value } \\
\text { (bilateral) }\end{array}$ & alpha \\
\hline Experimental group & 20 & 0 & 5.5 & 18.75 & 10.825 & 4.265 & 0.166 & 0.584 & 0.05 \\
\hline Control group & 20 & 0 & 6.75 & 18.50 & 10.263 & 3.215 & 0.183 & 0.458 & 0.05 \\
\hline
\end{tabular}


The pre-test results show that the control group achieved an average score of 10.263 , while experimental group achieved an average score of 10.825 . The difference is about 0.562 for the experimental group. To verify the importance of this difference, we use the student t-test to compare the averages of two independent samples. We first test the normality of the two samples using the Kolmogorov-Smirnov test. The data is called normal distribution if the value of Kolmogorov-Smirnov is greater than the significant value (0.05) [38]. Table 6 shows that the value of the experimental group is 0.584 while the value of control group is 0.458 . So, both of the samples have normalized distribution according to the normality criteria test from the value of Kolmogorov Smirnov. Next, we test the difference between the variances using Fisher's F Test; the result of the comparison is given by Table 7:

Table 7. Comparison of variances- Fisher F test / bilateral test (Pretest)

\begin{tabular}{|c|c|}
\hline 95\% confidence interval around the variance ratio: $[0.225 ; 1.436]$ \\
\hline Ratio & 0.568 \\
\hline F (Observed value) & 0.568 \\
\hline F (Critical value) & 2.526 \\
\hline DDL1 & 19 \\
\hline DDL2 & 19 \\
\hline p-value (bilateral) & 0.227 \\
\hline alpha & 0.05 \\
\hline
\end{tabular}

According to Table 7, the p-value is greater than the alpha level. A p-value of 0.227 does not enable us to reject the null hypothesis $\left(\mathrm{H}_{0}\right.$ the ratio between variances is equal to 1), there is no significant difference between the variances of the tested groups. This result shows that we can use the T-test to compare between the averages. Table 8 shows the results of the performed test.

Table 8. T-test for two independent samples / bilateral test (Pretest)

\begin{tabular}{|c|c|}
\hline 95\% confidence interval around the difference in means: $[-1.855 ;$ \\
$2.980]$
\end{tabular}

Since the calculated p-value is higher than the alpha threshold significance level $(0.640>0.05)$, the null hypothesis $\left(\mathrm{H}_{0}\right.$ the difference between the means is equal to 0 ) cannot be rejected. It can therefore be concluded that there is no significant difference between the averages of the tested groups. This result allows us to validate our experimental model based on a pre-test and post-test.

\subsection{Comparing the Average Score of the Two Groups Based on Post-Test}

The analysis of the post-test results of the two groups is presented in the Figure 3 and in Tables 9, 10 and 11.

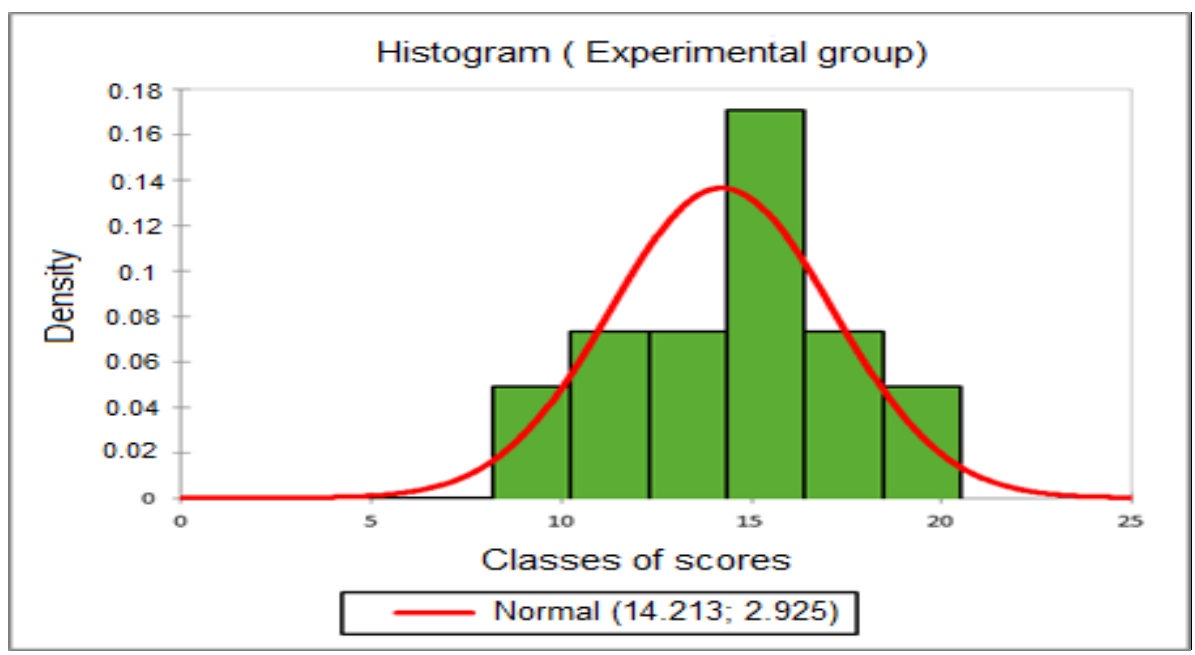




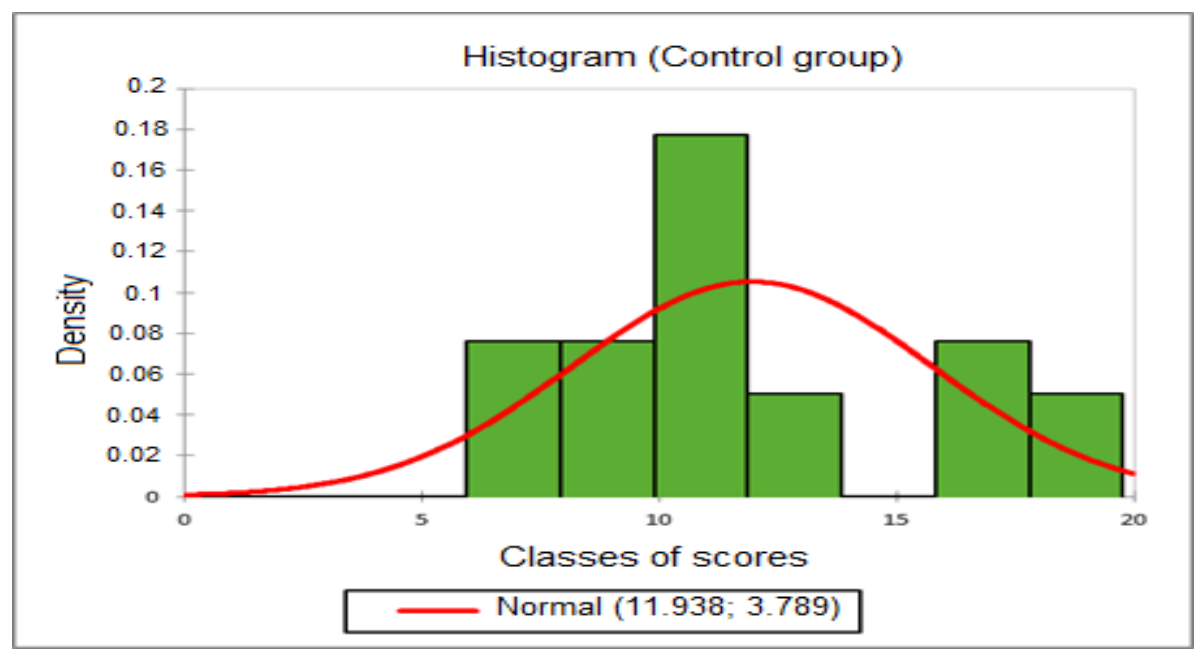

Figure 3. Graphs of the Normality Test for the posttest results

Table 9. Descriptive statistics and Kolmogorov-Smirnov test for the posttest results

\begin{tabular}{|c|c|c|c|c|c|c|c|c|c|}
\hline Variable & Observations & $\begin{array}{c}\text { Obs. with } \\
\text { missing data }\end{array}$ & Min & Max & Average & S.D & D & $\begin{array}{c}\text { P-value } \\
\text { (bilateral) }\end{array}$ & alpha \\
\hline Experimental group & 20 & 0 & 8.25 & 19.50 & 14.213 & 3.001 & 0.139 & 0.784 & 0.05 \\
\hline Control group & 20 & 0 & 7.00 & 18.75 & 11.938 & 3.886 & 0.193 & 0.392 & 0.05 \\
\hline
\end{tabular}

The results show that the average of the experimental group in the post-test is 14.213 , while for the control group, the average value is 11.938 . For both of the groups, the averages of the post-test are higher than the averages of the pre-test; the difference is around 2.275 in favor of the experimental group. To verify whether this difference is significant to reject the null hypothesis that the experimented pedagogical device has no effect on pupils' results, we use the student T-test to compare the averages of two independent samples with a normal distribution (in Table $9 \mathrm{p}$-value of Kolmogorov-Smirnov is not significant for both of the samples). The results of the variances comparison and the averages are presented in the Tables 10 and 11.

Table 10. Comparison of variances - Fisher $\mathrm{F}$ test / bilateral test (posttest)

\begin{tabular}{|c|c|}
\hline 95\% confidence interval around the ratio of variances: $[0.236 ; 1.507]$ \\
\hline Ratio & 0.595 \\
\hline F (Observed value) & 0.597 \\
\hline F (Critical value) & 2.526 \\
\hline DDL1 & 19 \\
\hline DDL2 & 19 \\
\hline p-value (bilateral) & 0.269 \\
\hline alpha & 0.05 \\
\hline
\end{tabular}

Table 11. T-test for two independent samples / bilateral test (posttest)

\begin{tabular}{|c|c|}
\hline \multicolumn{2}{|c|}{ 95\% confidence interval around the difference in means: [0.052; } \\
\hline Difference & 2.275 \\
\hline $\mathrm{t}$ (observed value) & 2.072 \\
\hline$|\mathrm{t}|$ (Critical value) & 2.024 \\
\hline DDL & 38 \\
\hline p-value (bilateral) & 0.044 \\
\hline alpha & 0.05 \\
\hline
\end{tabular}

According to Table 10, the p-value calculated is greater than the significance level alpha $(0,269>0.05)$, we cannot reject the null hypothesis $\left(\mathrm{H}_{0}\right.$ the ratio between the variances is equal to 1 ) so the variances can be considered as homogeneous. While Table 11 indicates that the calculated $\mathrm{p}$-value is lower than the alpha significance level $(0,044<0.05)$, we must reject the null hypothesis $\left(\mathrm{H}_{0}\right.$ the difference between the averages is equal to 0$)$, and keep the alternative hypothesis $\left(\mathrm{H}_{\mathrm{a}}\right.$ the difference between the averages is different from 0 ). As a result, the experimental group has highly significant improvement compared with the traditional group. Thus, the problem-based learning method supported by simulation has a great influence on student understanding of the rotational equilibrium concepts. 


\subsection{The Improvement of Students' Conceptual Understanding}

To determine the improvement of students' conceptual understanding, we compare in this section the results of both of the group in pre-test and post-test by means of $\mathrm{N}-$ Gain test. Normalized Gain [39] is defined by Eq2:

$\mathrm{N}-$ Gain $=($ Posttest-Pretest $) /($ Maximum score-Pretest $)(2)$

This measurement gives the ratio of the raw conceptual gain (post-test and pre-test) compared to the maximum possible gain. The results of the comparison between the students' conceptual understanding improved values of the two groups are presented in the Table 12.

Table 12. Results of the test in terms of standardized learning gain

\begin{tabular}{|c|c|c|c|}
\hline & Pretest & Posttest & N-Gain \\
\hline Control group & 10.263 & 11.938 & 0.172 \\
\hline Experimental group & 10.825 & 14.213 & 0.369 \\
\hline t-test & 0.471 & 2.072 & 1.031 \\
\hline
\end{tabular}

Before performing the treatment, there is no significant difference between the groups $(\mathrm{p}=0.640)$, but after the experiment, the simulation group achieved significantly greater conceptual gains $(p=0.044)$. According to the test scores gain in the normalized conceptual learning, we note that the conceptual understanding of the experimental group has been improved compared to the traditional group, since the difference between the obtained results is more significant $(t=1.031, p=0.044)$. As a general finding, the standardized learning gains for all questions, as indicated by Hake [39], it corresponds to a moderate improvement in the standardized learning gain for the experimental group (0.369) and a low qualified gain level (0.172) for the control group.

To determine the effect of the simulation product on student understanding improvement based on the concept, we compare the students' average score of both of the groups for each concept; students' level understanding of the concept is indicated in percentage. The results of the comparison test between the two groups based on concept are presented in Table 13.

We remark from the data shown in the Table 13 that the post-test score for both groups is higher than the pre-test score for all concepts:

- For the concept of force and inventory, in pre-test, the experimental group has 68.330 , while control group has 81.664. After applying the given treatment and taking post-test data, the experimental group scored 79.997, while control group had 88.331. The average $\mathrm{N}-$ Gain of the experimental group $(0.368)$ is almost equal to the control group (0.363). So, we can conclude that for the concept of force and inventory, the educational devices used by the experimental group did not have a significant impact regarding those used by the control group.

- For the concept of torque, the pre-test data shows that the control group obtains a score of 55.274, and the experimental group has 61.385. After implementing the treatment in both of the groups, the post-test score of the control group becomes 62.635, and the experimental group score becomes 71.302. The experimental group has marked an average score $(0.257)$ of N-Gain factor, which is greater than the $\mathrm{N}$-Gain score of the control group (0.165). We can conclude that the experimental group has developed a good understanding improvement of the torque concept better than the control group; this conclusion leads us to confirm that the treatment by PBL using Drawbridge simulation can be considered as a good alternative of the traditional method that can be used to improve the understanding of the torque concept.

- For the concept of Newton's second law for rotation, the pre-test score of the control group is 36.094, while pre-test score of the experimental group is 40.000. After applying the given treatment, the post-test score has been improved for both of the groups; the experimental group achieved 68.826 , and the control group achieved 45.157. The average $\mathrm{N}$-Gain of the experimental group (0.481) is greater than the control group (0.142), we can conclude that the understanding of Newton's second law of rotation concept using the problem-based learning approach with the integration of Drawbridge simulation is better than the traditional method.

Table 13. Comparison of the average of pre-test and post-test score between control group and experimental group based on concept

\begin{tabular}{|c|c|c|c|c|c|c|}
\hline \multirow{2}{*}{ Concept } & \multicolumn{3}{|c|}{ Control Group } & \multicolumn{3}{c|}{ Experimental Group } \\
\cline { 2 - 8 } & Pre-test & Post-test & N-Gain & Pre-test & Post-test & N-Gain \\
\hline Force and Inventory & 81.664 & 88.331 & 0.363 & 68.330 & 79.997 & 0.368 \\
\hline Torque & 55.274 & 62.635 & 0.165 & 61.385 & 71.302 & 0.257 \\
\hline Newton's second law for rotation & 36.094 & 45.157 & 0.142 & 40.000 & 68.826 & 0.481 \\
\hline
\end{tabular}


As a result, the problem-based learning approach combined with the interactive simulation has a great impact on improvement of concepts understanding compared to the traditional methods and tools. In our experience we assessed student understanding in rotational equilibrium topic based on three concepts, we found that the experimental group has an N-Gain average value higher than the control group for two fundamental concepts. Therefore, teaching with a problem-based learning method integrating the interactive simulation can be an effective solution to improve the understanding performance level of Moroccan high school students.

\section{Conclusions}

The aim of this pilot study is to compare the development of the conceptual understanding of two groups of learners belong to common core science in Moroccan high school. The experimental group uses the problem-based learning method with the integration of interactive simulation, while the second group uses the traditional method. The obtained results show that the experimental group learners have shown a significant gain of performance compared to the learners of the traditional group. The comparison of post-test average scores was significantly different after it was almost equal in the pre-test. The understanding improvement is primarily focused on two main concepts of the rotational equilibrium course; they are torque and the Newton's second law for rotation. These results confirm once again that the students' understanding using simulation is better compared to the traditional method. Indeed, White and Frederiksen [40] showed that the use of the computer simulation 'Thinker Tools' in physics enabled secondary school students to demonstrate a better understanding and interpretation of the forces acting on a moving object than higher education students who had received traditional instruction. Also, Droui et al. [41] stated positive effects of the use of a simulation of Newtonian laws in a problem-solving context on the conceptual understanding of Newtonian mechanics. In addition, Jimoyiannis et al. [42] assert that the use of computer simulations leads to the development of a functional understanding of the velocity and acceleration concepts in projectile movements. In another study, Gambari et al. [43] found that the students' performances were better improved thanks to the computer simulation. Based on this, they recommended that physics and chemistry teachers should use computer simulations to improve their students' performance and motivation.

Moreover, the teacher noted that students of the experimental group have shown, during the problem-solving steps, a high level of motivation and interaction compared to the control group. This observation is supported by the results of several experimental studies that examined the effect of interactive simulation on motivation, interaction and engagement [44,45]. The study [45] compared between the understanding of two groups, the first group learned the Archimedes thrust course using interactive simulation and the other through a real experiment. Among the results extracted from this study is that there is a significant convergence in the performance between both of the groups, this result makes the authors conclude that simulation can be an effective alternative to the absence of the real experiment. In the same context, Zakaria [46] compared between a control group learned using real experiment, and an experimental group learned using a combination of real and virtual experiment, he indicated that the replacement of real experiment with virtual experiments in some specific part of the experience has a positive effect on the students' conceptual understanding of electrical circuits.

Thus, these beneficial results enable us to conclude with sufficient confidence that: the traditional method no longer has a motivating effect on students; interactive simulation can beat real experience in creating motivational learning environments, and so improving the understanding and the acquisition of skills in case of experimental equipment shortage in the school laboratories, or when it is difficult to conduct a particular experiment because of a lack of time or because the equipment is too expensive or dangerous for the student. Interactive simulations in this circumstance can be an effective alternative. Simulations can also be included in educational practices as a support or supplement to the real experience.

The difference between two independent groups in terms of learning is usually explained by reference to the contributions of neuroscientists and cognitive psychologists in this field. The neuroscientist Hebb [47] believes that our knowledge is encoded in networks or assemblies of neurons. The process of acquiring this knowledge is described by the fact that, after the presentation of stimuli, impulses circulate in a given neural network and polarize it [48]. During the process of accumulating knowledge in the brain, the learner integrates the existing neural networks (pre-acquired) into a new network via frequent exercises or by other methods specific to the activation of the mental object. The process will increase when the subject is attentive [49].

In the same vein, cognitive psychologists highlight a number of factors whose impact is of primary importance on learning. Among the factors mentioned, we should note those related to the information organization, the repetition and motivation of the learner [50].

In general, the process of acquiring, accumulating and exploiting knowledge requires considerable intellectual efforts, so the pedagogical system should provide measures to support the learner's motivation if attention must be preserved throughout the learning process. In fact, improving the quality of learning requires the following 
elements:

- The attention is used to select information and act directly in the process of memorizing information.

- The action increases the amount of information retained.

- The feedback is benevolent; and so practical since it allows us to obtain an interesting review of what we have just done.

- The practice and repetition of a task frees a part of our brain to accumulate new information.

Referring to the potentials offered by Problem-based learning using simulation, we find that all requirements for improving the learning process are met when adopting this method in an appropriate pedagogical manner. The use of visual effects in the process of asking questions, manipulating variables and monitoring results is not familiar to the learner. Through these characteristics, the simulation helps to attract the learner's attention and limiting her/his work to tasks directly related to the targeted learning [51]. Simulation also offers the learner the right to learn at her/his own rhythm [52]. The simulation supports the learner's initiative, and gives $\mathrm{him} / \mathrm{her}$ the right to stop and repeat the learning process if necessary [45]. Indeed, the simulation makes the learner active and allows him/her to do an instant feedback [53]. So, the superiority demonstrated by the experimental group can be explained by all these aforementioned potentials.

Finally, it should be noted that this type of teaching compared to the traditional method is somewhat time-consuming and requires from teachers to demonstrate special skills; whether in planning, managing or monitoring the results (educational programs must be reduced by a qualitative rather than quantitative approach). We also point out that the computer room does not meet the aspirations for the sustainable use of technology in teaching practices (computers must be installed in the physics classroom).

\section{Appendix 1: Test Questions}

1. The Figure 4 presents a vehicle composed of several solid objects.

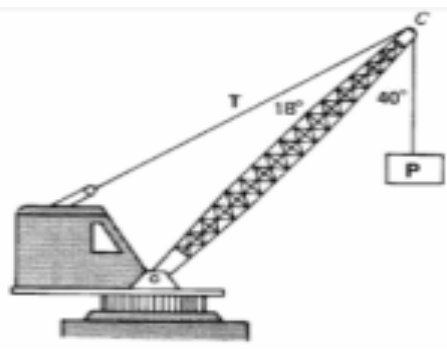

Figure 4

i). Among these objects, determine only one likely to rotate around a fixed axis, and define this axis.

ii). Make an inventory of the forces exerted on the solid you have chosen.

iii). Represent these forces without taking the scale.

2. We hang two masses at different points of a homogeneous disc rotatable around a fixed axis passing through its center, as shown in the Figure 5.

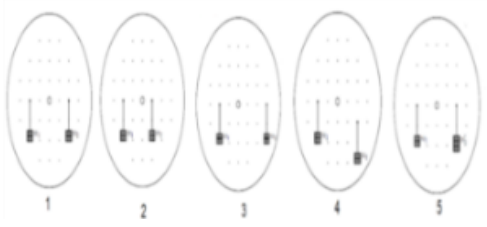

Figure 5

i). Is the disc weight able to rotate it around its axis?

ii). Complete the following table:

\begin{tabular}{|c|c|c|c|c|c|}
\hline Disc number & 1 & 2 & 3 & 4 & 5 \\
\hline Weights & $\mathrm{W}_{1}=\mathrm{W}_{2}$ & $\mathrm{~W}_{1}=\mathrm{W}_{2}$ & $\mathrm{~W}_{1}=\mathrm{W}_{2}$ & & $\mathrm{~W}_{2}<\mathrm{W}_{1}$ \\
\hline Lever arm & $\mathrm{L}_{1}=\mathrm{L}_{2}$ & & & & \\
\hline The rotational effect & & $\begin{array}{c}\text { The disc rotates } \\
\text { counterclockwise }\end{array}$ & & Equilibrium & \\
\hline
\end{tabular}


iii). What do we call the effect of rotation of a force on an object?

iv). What does this effect depend on?

3. Among the following sentences, choose the wrong one?

If a force $\overrightarrow{\mathrm{F}}$ parallel to the axis of rotation is exerted on a rotatable object, the latter will rotate.

If the effect line of the force $\vec{F}$ intersects with the axis of rotation of the rotatable object, the latter does not rotate. A force $\vec{F}$ perpendicular to the axis of rotation of the rotatable object causes a rotation.

4. Which of the following situations would produce the greatest torque?

a)

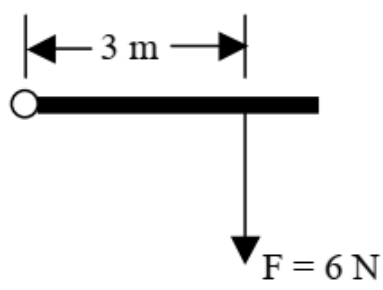

b)

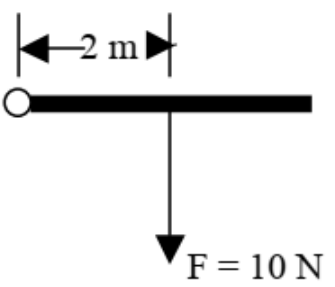

c)

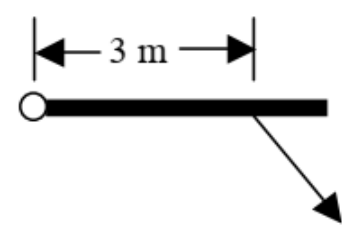

d)

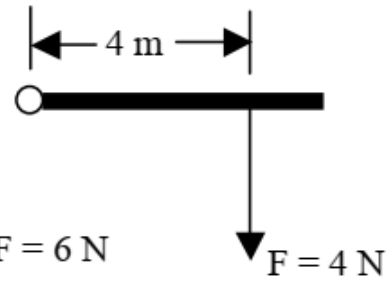

5. Figure 6 shows a meter stick which is balanced at the $50 \mathrm{~cm}$ mark. Three masses are hanging from the meter stick, as shown below; the numbers in the diagram represent the actual meter stick markings. What is the value of $M$ that can put the system in rotational equilibrium?

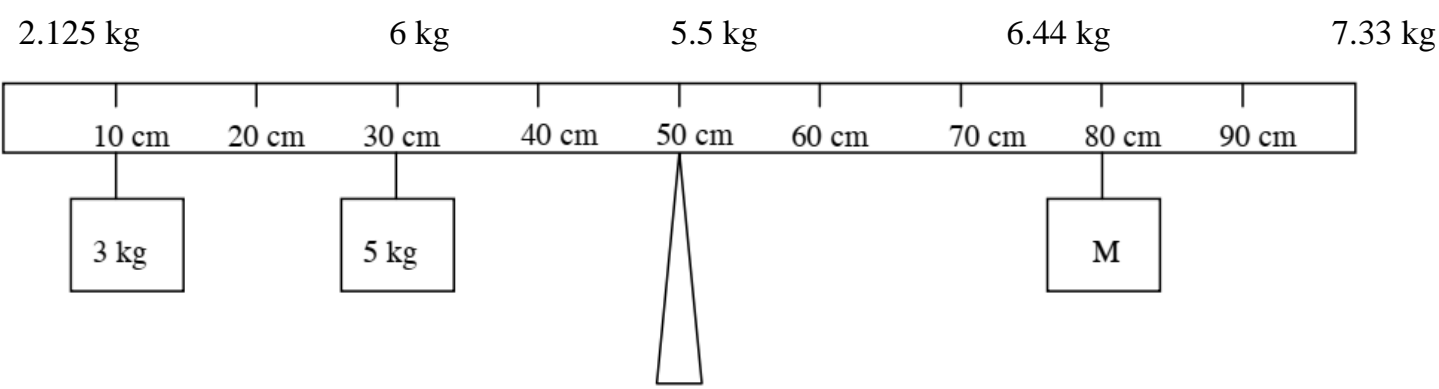

Figure 6

6. You want to lift a huge elephant (its mass is $7000 \mathrm{~kg}$ ), as shown in Figure 7.

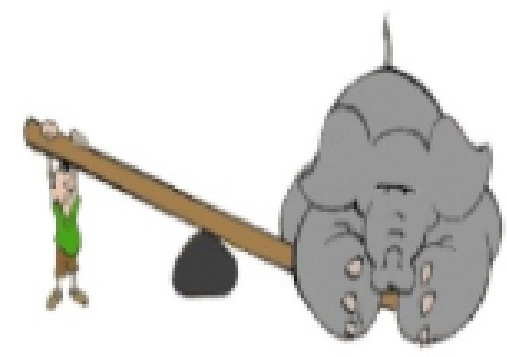

Figure 7

We assume that the lever mass is zero and that there is no friction.

i). Is it possible? If yes, show how?

7. Three torques act on an object. They have values of $3.0 \mathrm{Nm}$ clockwise; $6.0 \mathrm{Nm}$ Counterclockwise; and 7.0 Nm counterclockwise. Which one of these additional torques can be used to put the object into rotational equilibrium?

$2 \mathrm{Nm}$ clockwise $10 \mathrm{Nm}$ counterclockwise
$2 \mathrm{Nm}$ counter-clockwise $10 \mathrm{Nm}$ clockwise
4 Nm clockwise 
8. We want to lift the drawbridge using the mass $\mathrm{K}$ as shown in Figure 8.

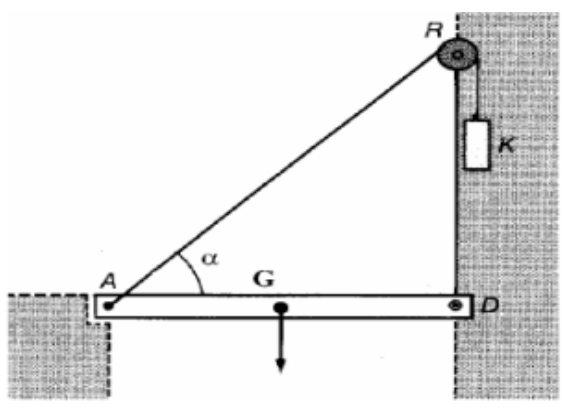

Figure 8

i). Trace the lever arms of all the forces exerted on the bridge AD.

ii). Express the lever arm for cable tension as a function of the angle $\alpha$ and length of bridge.

iii). Torque value of the cable tension has maximum value if angle $\alpha$ is:
$90^{\circ}$
0
$45^{\circ}$
$180^{\circ}$

iv). What is the condition that must be fulfilled in order to rotate the bridge?

v). Suppose that when trying to lift the bridge, the cable is cut. Explain this result using the torque concept.

\section{REFERENCES}

[1] Alessi, S. M. \&. Trolip S. R (1985), Computer-Based Instruction: Methods and Development. Englewood Cliffs, New Jersey: Prentice-Hall, Inc. https://doi.org/10.1016/074 7-5632(86)90005-1

[2] Adams, W.K., Reid, S., LeMaster, R., McKagan, S.B., Perkins, K.K., Dubson, M. \& Wieman, C.E. (2008). A Study of Educational Simulations Part I - Engagement and Learning. Journal of Interactive Learning Research, 19(3), 397-419. Waynesville, NC: Association for the Advancement of Computing in Education (AACE). Retrieved July 2, 2020 from https://www.learntechlib.org/p rimary/p/24230/.

[3] Kiboss, J. K., Ndirangu, M., \& Wekesa, E. W. (2004). Effectiveness of a computer-mediated simulations program in school biology on pupils' learning outcomes in cell theory. Journal of Science Education and Technology, 13(2), 207 213.

[4] Baltzis, K. B., \& Koukias, K. D. (2009). Using laboratory experiments and circuit simulation IT tools in an undergraduate course in analog electronics. Journal of Science Education and Technology, 18(6), 546-555. https://www.learntechlib.org/p/76294/.

[5] Cantin, R., Lacasse, D. et Roy., L. (1996). Apprentissage par problème, activité de synthèse et épreuve synthèse. Pédagogie collégiale, 10 (2): 5-10.

[6] MacKinnon, M. M. (1999). Core elements of student motivation in problem-based learning. New Directions for Teaching and Learning, 78, 49-58.

[7] Barrows, H. S., \& Myers, A. C. (1993). Problem-based learning in secondary schools, (Unpublished Monograph). Springfield, IL: Problem-based Learning Institute. Lanphier high school and Southern Illinois University Medical

School.

[8] Torp, L. \& Sage, S. M. (2002). Problem as possibilities: Problem-based learning for K-16 education (2nd ed.). Alexandria, VA: Association for Supervision and Curriculum Development.

[9] Jonassen, D. H., Peck K. L. \& Wilson, B. G. (1999). Learning with Technology: A Constructivist Perspective. New Jersey: Merril. p. 2-11.

[10] Roth, W. M., Roychoudhury., A. (1993). The development of science process skill in authentic context. Journal of Research in Science Teaching, 30, 127-152. https://doi.org/10.1002/tea.3660300203

[11] Marcel Lebrun. Impacts des TIC sur la qualité des apprentissages des étudiants et le développement professionnel des enseignants : vers une approche systémique. STICEF (Sciences et Technologies de l'Information et de la Communication pour l'Éducation et la Formation), ATIEF, 2011, 18, 20 p. ffhal-00696443f

[12] Collins, A. et Brown, J. S. (1986). The new apprenticeship: Teaching students the craft of reading, writing and mathematics. In L. B. Resnick (dir.), Cognition and instruction: Issues and agendas (p. 76-95). Hillsdale, NJ: Erlbaum.

[13] de Jong, T., Martin, E., Zamarro, J-M., Esquembre, F., Swaak, J., \& van Joolingen, W. (1999). The integration of computer simulation and learning support: an example from the psysics domain of collisions. Journal of research in science teaching, 36(5), 597-615.

[14] Programme National d'Evaluation des Acquis des élèves du tronc commun (PENA). Rapport analytique. Conseil supérieur de l'éducation de la formation et de la recherche scientifique, Maroc, 2016. Available on : https://www.csefrs.ma/wp-content/uploads/2017/02/Rappor t-PNEA-2016-FR-Final.pdf

[15] Provasnik S., Malley L., Stephens M., Landeros K., Perkins R., Tang J.H. Highlights From TIMSS and TIMSS 
Advanced 2015. National Center for Education Statistics, Institute of Education Sciences, U.S. Department of Education, Washington, November 2016.

[16] Benazet, P. (2004). Approche sémiotique des processus cognitifs du multimédia éducatif. Évaluation et préconisations. Thèse pour obtenir le grade de grade de Doctorat. université de Perpignan, Faculté des Lettres et Sciences Humaines.

[17] Jalal, K., Lotfi, A., Ahmed, R., \& Abdelilah, E. (2019). Are Educational Games Engaging and Motivating Moroccan Students to Learn Physics? International Journal of Emerging Technologies in Learning (IJET), 14(16), pp. 66-82.

[18] Guilbert, L. \& Ouellet, L. (1997). Étude de cas, Apprentissage par problèmes. Presses de l'Université du Québec, Ste-Foy, 136 pages.

[19] Savin-Baden, M., \& Major, C. H. (2004). Foundations of problem-based learning, Society for Research into Higher Education. New York : Open University Press.

[20] Gallagher, S. A., Stepien, W. J., Sher, B. T. \& Workman, D. (1995). Implementing problem-based learning in science classrooms. School Science and Mathematics, 95(3), 136146.

[21] Gredler, M. (2004). Games and simulations and their relationships to Learning. In D. H. Jonassen (Ed.), Handbook of research for educational communications and technology (2nd edition). Mahwah (NJ): Laurence Erlbaum Associates, p. 571-581.

[22] Winer, Laura R. ; Vazquez-Abad, J. (1981). Towards a Theoretical Framework for Educational Simulations. Simulation/Games for Learning, v. 11, n 3, p. 114-19 Fall.

[23] ISO 9241: Ergonomic requirements for office work with visual display terminals (VDTs) Google Scholar

[24] SENACH B. (1990). Evaluation ergonomique des interfaces homme-machine: une revue de la littérature. Rapport de recherche INRIA-Sophia Antipolis, Mars 1990.

[25] Deci, E. L. and Ryan, R. M. (1985). Intrinsic motivation and self-determination in human behavior. New York, New York: Plenum.

[26] Deci, E. L. and Ryan, R. M. (1991). A motivational approach to self: Integration in personality. In R. Dienstbier (ed.), Nebraska symposium on motivation: Vol. 38, Perspectives on motivation (p. 237-288). Lincoln, Nebraska: University of Nebraska Press.

[27] Fortier, M.S., Vallerand, R.J and Guay,F. (1995). Academic motivation and school performance: toward a structural model. Contemporary educational psychology, 20, 2576274.

[28] Gottfried, A. E. (1990). Academic intrinsic motivation in young elementary school children. Journal of educational psychology, 82, 525-538.

[29] Guay, F. and Vallerand, R. J. (1997). Social context, students' motivation, and academic achievement: towards a process model. Social psychology of education, 1, 211-233.

[30] Komarraju, M., Karau, S. J. and Schmeck, R. R. (2009). Role of the big five personality traits in predicting college students' academic motivation and achievement. Learning and individual differences, 19, 47-52.

[31] Deci, E. L. \& Ryan, R. M. (2000). Intrinsic and extrinsic motivations: classic definitions and new directions. Contemporary educational psychology, Vol.25, p 54-67.

[32] KELLER.J.M. (1983). Motivational design of instructions. In C.M. REIGELUTH, ed., instructional design theories and models: an overview of their current status. Hillsdale, NJ: Erlbaum.

[33] Lepper, M., Keavney, M., \& Drake, M. (1996). Intrinsic Motivation and Extrinsic Rewards: A Commentary on Cameron and Pierce's Meta-Analysis. Review of Educational Research, 66(1),5-32.

[34] Wlodkowski, R. J. (1985). Enhancing adult motivation to learn. San Francisco: Jossey-Bass Publishers.

[35] Nielsen, J. (1994). Heuristic evaluation. In J., Nielsen and R.L. Mack (Eds.), Usability Inspection Methods. John Wiley $\&$ Sons, New York.

[36] Addinsoft (2020). XLSTAT statistical and data analysis solution. Paris, France. https://www.xlstat.com

[37] McDermott, L. C. (1993). Guest Comment: How we teach and how students learn - A mismatch? American Journal of Physics, 61(4), 295-298.

[38] Minium, E. W., King, B. M., \& Bear, G. (1970). Statistical Reasoning In Psychology And Education Third Edition. New York: John Wiley\&Sons, Inc.

[39] Hake, R. R. (1998). Interactive-Engagement versus traditional methods: A six-thousand- student survey of mechanics test data for introductory physics courses. American Journal of Physics, 66 (1), 64-74. https://doi.org/10.1119/1.18809

[40] White, B. et Frederiksen, J. (2000). Technological tools and instructional approaches for making scientific inquiry accessible to all. In M. Jacobson and R. Kozma (Eds), Innovations in Science and Mathematics Education: Advanced Designs for Technologies of Learning (p. 321-359). Mahwah, NJ: Lawrence Erlbaum Associates.

[41] Droui, M., El Hajjami, A., Bouklah, M., \& Zouirech, S. (2013). Impact de l'apprentissage par problème sur la compréhension conceptuelle de la mécanique newtonienne. EpiNet: Revue électronique de l'EPI, 157.

[42] Jimoyiannis, A., \& Komis, V. (2001). Computer simulations in physics teaching and learning: a case study on students' understanding of trajectory motion. Computers \& Education, 36(2), 183-204.

[43] Gambari, I. A., Gbodi, B. E., Olakanmi, E. U., \& Abalaka, E. N. (2016). Promoting Intrinsic and Extrinsic Motivation among Chemistry Students Using Computer-Assisted Instruction. Contemporary Educational Technology, 7(1), 25-46.

[44] Durán, M. J., Gallardo, S., Toral, S. L., Martínez-Torres, R., \& Barrero, F. J. (2007). A learning methodology using Matlab/Simulink for undergraduate electrical engineering courses attending to learner satisfaction outcomes. International Journal of Technology and Design Education, 17(1), 55-73

[45] Cherif Alaoui Mrani, Abdelkrim El hajjami, Khalid El khattabi. "Effects of the Integration of PhET Simulations in 
Interactive Simulation on the Physical Sciences Conceptual Understanding of the Moroccan Common Core Learners

the Teaching and Learning of the Physical Sciences of Common Core (Morocco)." Universal Journal of Educational Research 8.7 (2020) 3014 - 3025. doi: 10.13189/ujer.2020.080730.

[46] Zacharia, Z. C. (2007). Comparing and combining real and virtual experimentation: an effort to enhance students' conceptual understanding of electric circuits. Journal of Computer Assisted Learning, 23(2), 120-132. https://doi.org/10.1111/j.1365-2729.2006.00215.x

[47] Hebb, D. (1980). Essay on mind. Hillsdale, NJ: Lawrence Rrlbaum.

[48] Brien, R., Bourdeau, J. \& Rocheleau, J. (1999). L'interactivité dans l'apprentissage : la perspective des sciences cognitives. Revue des sciences de l'éducation, 25 (1), 17-34. https://doi.org/10.7202/031991ar

[49] Frégnac, Y. (1994). Les mille et une vies de la synapse de Hebb. La Recherche, 267, 788-790.
[50] Marieb, R. N. et Laurendeau, G. (1993). Anatomie et physiologie humaines. Saint-Laurent: Éditions du renouveau pédagogique

[51] ORANGE C. (1992). Les logiciels de simulation : Substituts du réel ou véritables aides didactiques pour l'enseignement de la biologie-géologie ? In G.-L. Baron \& J. Baudé (Éd.). L'intégration de l'informatique dans l'enseignement et la formation des enseignants. Paris: INRP, p. $116-118$.

[52] El Hajjami, A.; El Mokri, A.; Ajana, L.; Chikhaoui, A. (2000). Approches analytiques de logiciels d'apprentissage des sciences physiques, Colloque Enseignement et Recherche en didactique des sciences « ERDS $2000 »$, p. 49-58.

[53] M. Windschitl, T. Andre. Using computer simulations to enhance conceptual change: The roles of constructivist instruction and student epistemological beliefs. Journal of Research in Science Teaching, 35(2), p. 145-160, 1998. 